\title{
Performance Assessment of a Variable-Rate Fertilizer Applicator
}

\author{
Ruixiu Sui ${ }^{1}$ \\ ${ }^{1}$ United States Department of Agriculture, Agricultural Research Service, Crop Production Systems Research \\ Unit, Stoneville, Mississippi, USA \\ Correspondence: Ruixiu Sui, United States Department of Agriculture, Agricultural Research Service, Crop \\ Production Systems Research Unit, Stoneville, Mississippi, USA. Tel: 1-662-686-5382. E-mail: \\ ruixiu.sui@ars.usda.gov
}

Received: September 10, 2018

Accepted: November 17, 2018

Online Published: January 15, 2019

doi:10.5539/jas.v11n2p25

URL: https://doi.org/10.5539/jas.v11n2p25

\begin{abstract}
The objective of this study was to test the performance of a Field-IQ sprayer control system which was interfaced with a John Deere liquid fertilizer applicator. The sprayer control system includes Case IH FM-1000 display integrated with DGPS, Field-IQ spray control with full harness, flowmeter and auto-range valve, and the pump. Tap water was used to simulate the UAN 32\% nitrogen fertilizer solution in the test. A total of 120 samples from 8 rows of the applicator in 5 application rates $(34,67,101,135$, and $168 \mathrm{~kg} / \mathrm{ha})$ were collected, and the data were analyzed for application uniformity and application rate accuracy of the system. Results showed the greatest variation from the application rate baseline among the rows was $10.1 \%$ and occurred at a swath-end row with the lowest application rate of $34 \mathrm{~kg} / \mathrm{ha}$. The rows in the middle section of the swath had the lower variation than the rows at the two swath-ends. The application uniformity increased as the application rate increased. The absolute error of application rate ranged from $1.3 \%$ to $6.5 \%$ with an average of $3.76 \%$. There was no significant difference between the selected application rate and actual application rate $(\mathrm{p}>0.8686)$.
\end{abstract}

Keywords: variable rate application, liquid fertilizer applicator, control system, precision agriculture

\section{Introduction}

Precision agriculture is the use of detailed information within agricultural fields to optimize production inputs on a spatially variable basis, rather than to apply uniform applications across the entire field. It allows producers to apply appropriate amounts of production inputs on each location in the field. This can not only maximize farm profit, but also minimize environmental impact.

Variable rate technology (VRT) plays an important role in precision agriculture. It involves the use of site-specific information in applying a desired rate of an agricultural input such as fertilizer at a specific site within a field. This practice demands accurate, reliable, and high-resolution VRT equipment to physically apply the materials in agricultural production.

Use of nitrogen $(\mathrm{N})$ fertilizer is one of the greatest cost inputs in crop production (Anonymous, 2018). Crop responses to $\mathrm{N}$ often varies spatially and temporally within a field (Vetch et al., 1995; Raun \& Johnson, 1999). Management practice of variable rate application (VRA) of N, which applies $\mathrm{N}$ site-specifically based on the crop needs, could generate economic benefit for producers and create positive environmental impacts (Yang et al., 2000; Koch et al., 2004; Saleem et al., 2013a; 2013b).

A fertilizer applicator usually equipped with a VRA controller and relevant software, and a GPS receiver. The GPS receiver determines the location of the applicator in the field. Based on the spatial information from the GPS and the data from the prescription map, the VRA controller generates electrical signal to control a mechanical actuator to apply fertilizer at a desired rate to that specific location in the field. For example, VRA liquid fertilizer applicators use servo valves, flow meters, and speed sensors to directly control the flow of the liquid fertilizer to achieve a desired application rate. As the applicator moves across the field, the VRA controller is constantly updated with the applicator location information provided by the GPS receiver and desired application rate at the location, and then adjusts the flow rate of the liquid fertilizer to match the desired rate by controlling the servo valve opening based on the inputs from the speed sensor and flow meter and the swath width of the applicator (Yang, 2000; Grisso et al., 2011). 
While VRT spray systems have been commercially available, some concerns about system performance remain, such as non-uniformity among nozzles and lack of accuracy in application rate. Schueller and Wang (1994) discussed some issues in spatially-variable control of fertilizer application. They concluded that the dynamics of the spatially-variable applicator affected its performance and command feedforward control improved the performance of the applicators. Fulton et al. (2001) assessed the accuracy of a variable-rate fertilizer applicator. They used a matrix of collection pans to gather the material spread by a spinner spreader truck and characterized the application variability of the spreader. They found that there was spread variability with the spinner spreaders, and the coefficient of the variations were above $20 \%$ for the average transverse spread patterns for both the 56.0 and $168.1 \mathrm{~kg} / \mathrm{ha}$ uniform tests. Anglund and Ayers (2003) tested the performance of a ground sprayer for applying chemicals at constant and variable application rates. They observed that the control system provided accurate application rate within $\pm 2.25 \%$ of the desired rate. Yang (2000) assessed the performance and field application accuracy of a VRT side dressing liquid fertilizer applicator. He reported that the mean application errors for UAN 32\% solution and liquid ammonium phosphate 10-34-0 liquid fertilizers were, respectively, 2.5 and $5.2 \%$ in one field test and 2.8 and $5.8 \%$ in the other.

The objective of this study is to characterize row-to-row uniformity and application rate accuracy of a VRT liquid fertilizer applicator.

\section{Material and Method}

\subsection{Variable-Rate Fertilizer Applicator}

A Field-IQ sprayer control system (Case IH, Racine, Wisconsin) was selected in this study. The system includes the Case IH FM-1000 display integrated with DGPS, Field-IQ spray control with full harness, flowmeter and auto range valve, and the pump. The system was interfaced with the distribution plumbing present on the liquid fertilizer applicator. This applicator delivers liquid fertilizer below the soil with coulter-mounted knife (Figure 1). Swath width of the applicator is $7.72 \mathrm{~m}$ in 8 rows with a row spacing of $96.5 \mathrm{~cm}$ (38 in).

The FM-1000 display, which consists of both software and hardware, is an advanced, full-featured field management system with an integrated GPS/GLONASS receiver for precision farming applications. The software runs on a $30 \mathrm{~cm}$ touch-sensitive, color LCD screen. The FM-1000 display is compatible with many products for automated steering, including AutoPilot, EZ-Pilot, EZ-Steer, Field IQ, True Guide, True Tracker.

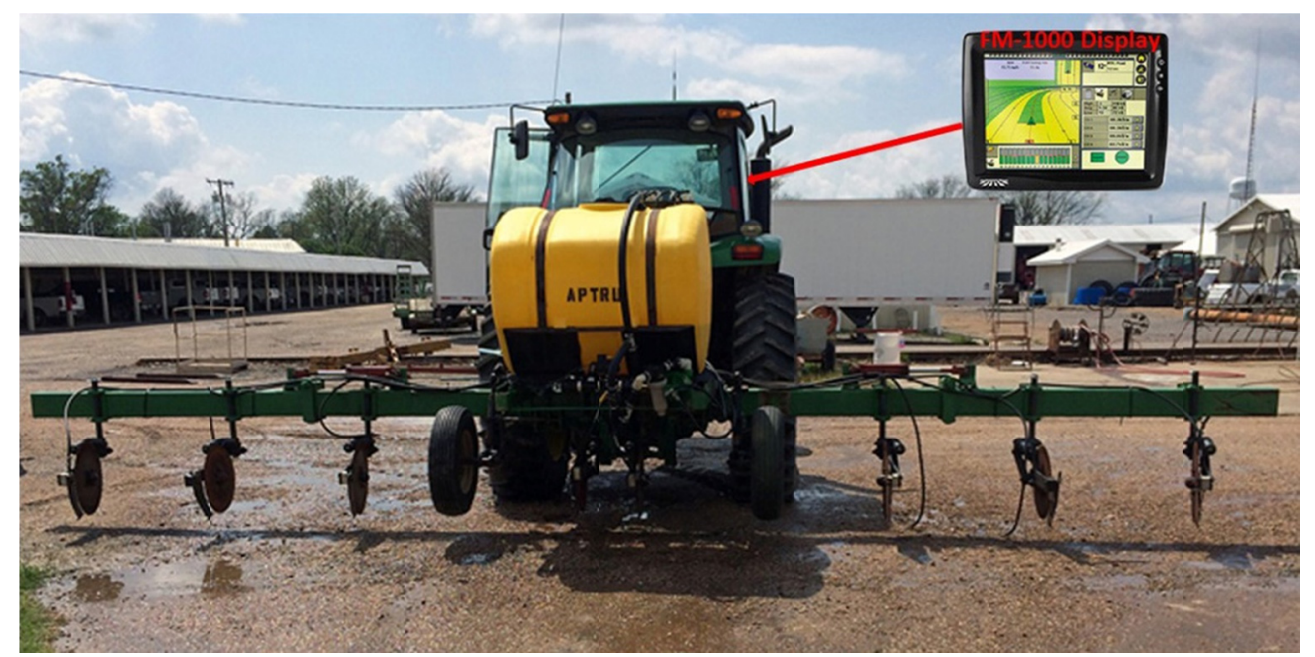

Figure 1. Field-IQ sprayer control system installed on a liquid fertilizer applicator with the FM-1000 display inside the cabin

\subsection{Test Procedure and Data Analysis}

After installation of the spray control system, the flows at each row was measured to evaluate if the system was correctly delivering the liquid fertilizer at the flow rate set in the FM-1000 display. To accomplish this, a simulated groundspeed of $11.3 \mathrm{~km} / \mathrm{h}(7 \mathrm{mph})$ was set as the test speed. Application rates of 34, 67, 101, 135, and $168 \mathrm{~kg} / \mathrm{ha}(30,60,90,120$, and $150 \mathrm{lb} / \mathrm{ac})$ were used in the test. Each application rate was randomly repeated three time. To easily collect the effluent samples, the tube to the coulter-mounted knife was disconnected at each 
row, and a container was used to catch the effluent from the tube (Figure 2). In every round of sampling, an applicator was set at a randomly selected application rate, activated and allowed to come to steady-state for three minutes. Then the effluent for each knife (row) was collected for 60 seconds as one effluent sample. Eight samples were obtained for 8 rows in one round of sampling. With 5 application rates and three replications, 120 total samples were taken in this study. The effluent samples were weighed using a HD-150 scale (My Weight, Phoenix, AZ), and their volumes were calculated using their weights and the effluent density using the equation below:

$$
\text { Volume }=\frac{\text { Weight }}{\text { Density }}
$$

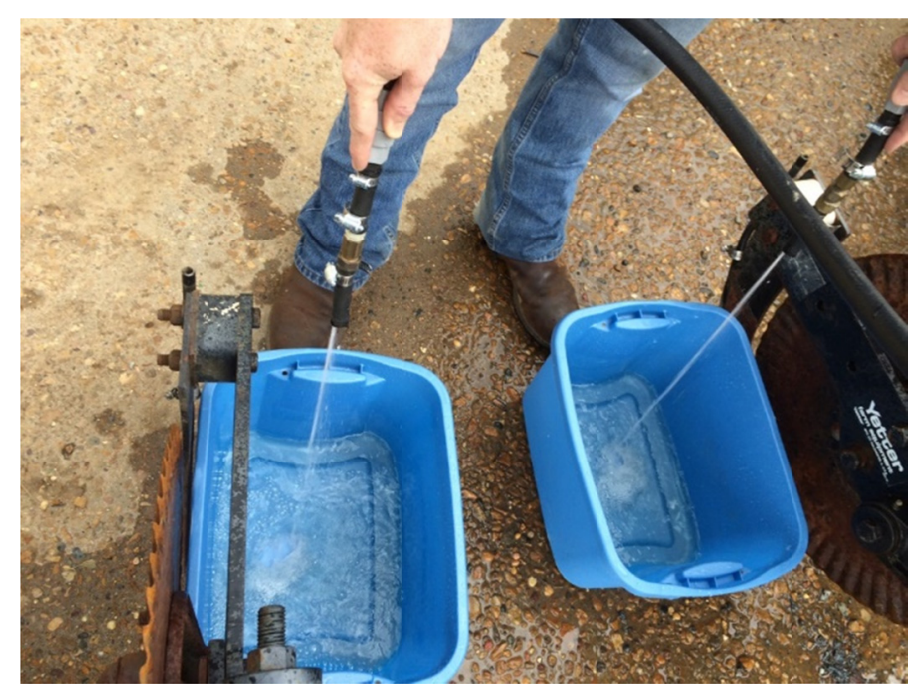

Figure 2. The effluent from the knife tube was collected to determine the flow rate

In this study, tap water was used as the effluent to simulate the liquid fertilizer UAN 32\% Solution. The UAN $32 \%$ Solution was a nitrogen fertilizer solution composed of urea and ammonium nitrate. It was widely used in U.S. One liter of UAN $32 \%$ Solution contains $424 \mathrm{~g}$ of nitrogen $(\mathrm{N})$.

The swath width, test speed, and sampling time were used to calculate the application area during the sampling time. Effluent volume and N content of the UAN 32\% Solution was used to determine the total amount of N applied during the sampling time. Then the measured application rate was obtained by dividing the total $\mathrm{N}$ by the application area and compared to the application rate which was set in the FM1000 display for application rate accuracy of the control system. The flow rate at row was calculated for determination of application uniformity along the entire swath.

\section{Results and Discussion}

Figure 3 showed the results of the uniformity tests for all application rates. Each application rate was tested three times to yield three replications. Amounts of effluent in the three replications were averaged for each row, and the mean of these values in the 8 rows was used as baseline to compute the deviations shown in Figure 3 . They were expressed as percent error relative to the mean of all rows for a given application rate. The greatest variation from the application rate baseline among the rows was $10.1 \%$ and occurred at row-1 with the application rate of $34 \mathrm{~kg} / \mathrm{ha}$. In general, the rows in the middle section of the swath (row 3,4,5) had a lower variation than the rows at the two ends. 


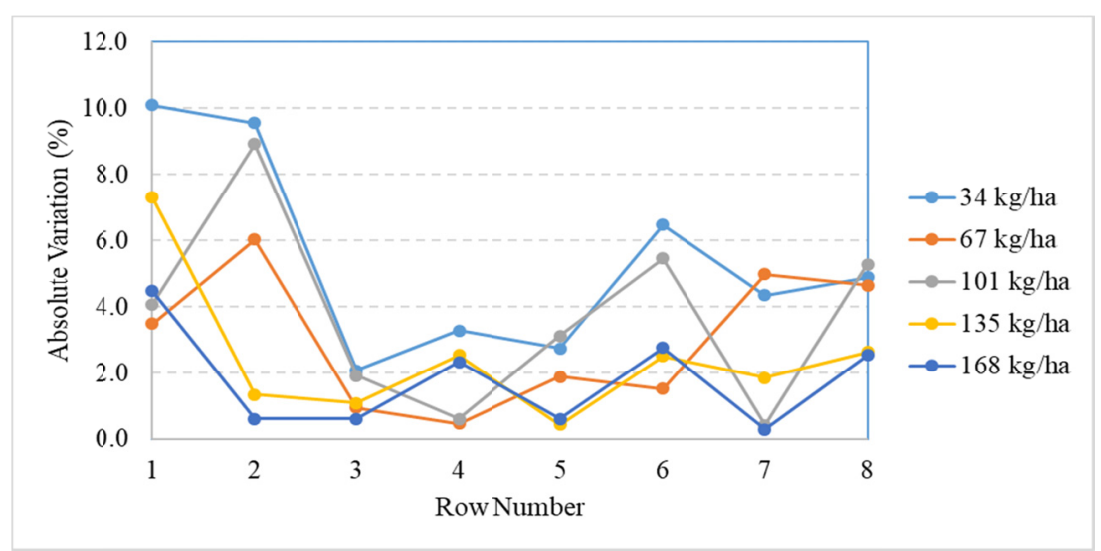

Figure 3. Absolute flow rate variation of each row at all application rates

Figure 4 showed the change of the absolute variation with the application rate. It was observed that there is a trend that the variation of flow rate decreases as the application rate increases. Greater application uniformity could be achieved using higher application rate.

The sum of the effluent amounts of 8 rows was calculated at a given application rate, and the total effluent value was used to determine the actual application rate. Figure 5 illustrated the measured application rates along with the application rates selected in the FM-1000 display. Minimum absolute error of the application rate is $1.3 \%$ at the rate of $34 \mathrm{~kg} / \mathrm{ha}$ while the maximum absolute error of $6.5 \%$ occurred at the rates of $67 \mathrm{~kg} / \mathrm{ha}$ and $168 \mathrm{~kg} / \mathrm{ha}$. The average absolute error of application rate was 3.76\%. Except at $135 \mathrm{~kg} / \mathrm{ha}$, the actual application rates are lower than the selected rates (Table 1). These could possibly be caused by the fraction loss of the effluent.

The ideal flow rate and actual mean flow rate at an application rate selected were given in Table 1. An ANOVA analysis of the flow rates was performed using SAS software (SAS Institute Inc., Cary, NC). The result indicated that there is no significant difference between the ideal rates and the actual rates $(\mathrm{p}>0.8686)$.

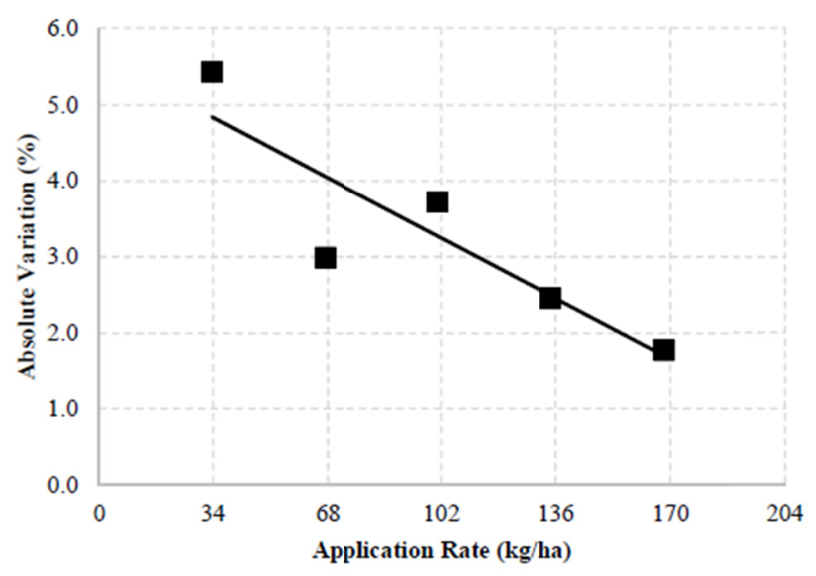

Figure 4. Results indicated the variation of flow rate across the swath width of the applicator decreased as the increase of application rate 


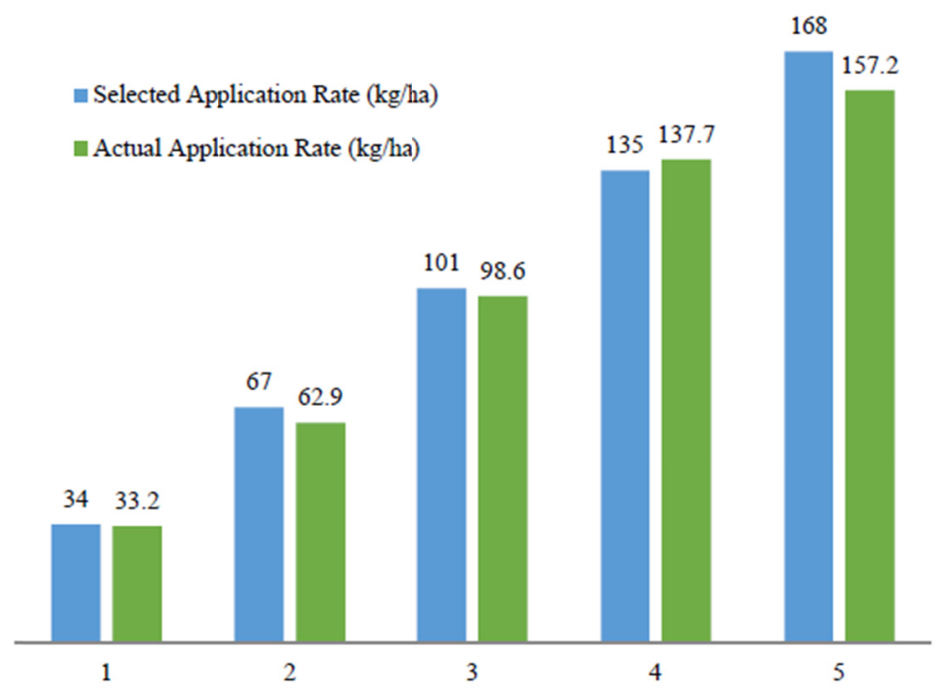

Figure 5. Comparison of the set application rate in the FM1000 display to the actual application rate measured in the test

Table 1. Accuracy of application rate of the spray control system

\begin{tabular}{lllll}
\hline $\begin{array}{l}\text { Selected Appl. Rate } \\
\text { (kg/ha) }\end{array}$ & $\begin{array}{l}\text { Ideal Row Flow Rate } \\
\text { (1/min) }\end{array}$ & $\begin{array}{l}\text { Actual Row Flow Rate } \\
(\mathbf{l} / \mathbf{m i n})\end{array}$ & $\begin{array}{l}\text { Actual Appl. Rate } \\
\mathbf{( k g} / \mathbf{h a})\end{array}$ & $\begin{array}{l}\text { Application Rate Error } \\
\mathbf{( \% )}\end{array}$ \\
\hline $\mathbf{3 4}$ & 1.44 & 1.42 & 33.2 & -1.3 \\
$\mathbf{6 7}$ & 2.87 & 2.69 & 62.9 & -6.5 \\
$\mathbf{1 0 1}$ & 4.31 & 4.21 & 98.6 & -2.2 \\
$\mathbf{1 3 5}$ & 5.75 & 5.88 & 137.7 & 2.3 \\
$\mathbf{1 6 8}$ & 7.18 & 6.71 & 157.2 & -6.5 \\
\hline
\end{tabular}

\section{Summary}

A Liquid fertilizer applicator equipped with a Field-IQ sprayer control system was tested for application uniformity and accuracy of application rate. The applicator had eight rows with a swath width of $7.7 \mathrm{~m}$. A coulter-mounted knife was used to deliver liquid fertilizer at each row. The application rate was changed by adjusting the effluent flow rate at each row. During the test, tap water was used as the effluent to simulate the UAN 32\% nitrogen fertilizer solution. Effluent samples for each row were collected at application rate 34, 67, 101,135 , and $168 \mathrm{~kg} / \mathrm{ha}$, respectively. The samples were weighed, and their weight values were analyzed to find the application uniformity and the application rate accuracy. Results showed that the rows in middle of the swath had a lower flow rate variation than the rows at the two swath-ends. The application uniformity increased as the application rate increased. The absolute error of application rate ranged from $1.3 \%$ to $6.5 \%$ with an average of $3.76 \%$. There was no significant difference between the selected application rates and actual application rates.

The uniformity and accuracy of the VRT equipment used in precision agriculture should be considered when prescriptions are written, or management zones are developed. It would not make much sense to write high resolution prescriptions for precision management when the VRT equipment is incapable of accommodating the same level of accuracy. The variable rate applicator tested in this study has been used in the research of variable rate $\mathrm{N}$ application for several years. In general, this control system could provide the application accuracy required in our research.

\section{Disclaimer}

Mention of a trade name, proprietary product, or specific equipment does not constitute a guarantee or warranty by the U. S. Department of Agriculture and does not imply approval of the product to the exclusion of others that may be available.

\section{References}

Anglund, E. A., \& Ayers, P. D. (2003). Field evaluation of response time for a variable rate (pressure-based and injection) liquid chemical applicator. Appl Eng Agric, 19(3), 273-282. https://doi.org/10.13031/2013.13659 
Anonymous. (2018). Guidelines for estimating crop production cost - 2018. Retrieved October 22, 2018, from https://www.gov.mb.ca/agriculture/farm-management/financial-management/pubs/cop-crop-production.pdf

Fulton, J. P., Shearer, S. A., Chabra, G., \& Higgins, S. F. (2001). Performance assessment and model development of a variable-rate spinner-disc fertilizer application. Trans ASABE, 44(5), 1071-1081. https://doi.org/10.13031/2013.6429

Koch, B., Khosla, R., Frasier, W. M., Westfall, D. G., \& Inman, D. (2004). Economic feasibility of variable-rate nitrogen application utilizing site-specific management zones. Agron J., 96, 1572-1580. https://doi.org/ 10.2134/agronj2004.1572

Raun, W. R., \& Johnson, G. V. (1999). Improving nitrogen use efficiency for cereal production. Agronomy Journal, 91, 357-363. https://doi.org/10.2134/agronj1999.00021962009100030001x

Saleem, S. R., Zaman, Q. U., Schumann, A. W., Madani, A., Chang, Y. K., \& Farooque, A. A. (2013a). Impact of variable rate fertilization on nutrient losses in surface runoff for wild blueberry fields. Appl Eng in Agric, 30(2), 179-185.

Saleem, S. R., Zaman, Q. U., Schumann, A. W., Madani, A., Farooque, A., \& Percival, D. C. (2013b). Impact of variable rate fertilization on subsurface water contamination in wild blueberry cropping system. Appl Eng Agric, 29(2), 225-232. https://doi.org/10.13031/2013.42653

Schueller, J. K., \& Wang, M. (1994). Spatially-variable fertilizer and pesticide application with GPS and DGPS. Comput Electron Agr, 11, 69-83. https://doi.org/10.1016/0168-1699(94)90053-1

Vetch, J. A., Malzer, G. L., Robert, P. C., \& Huggins, D. R. (1995). Nitrogen specific management by soil condition: Managing fertilizer Nitrogen in corn. In P. C. Robert, R. H. Rust, \& W. E. Larson (Eds.), Site specific management for agricultural systems. Madison WI: ASA/CSSA/SSSA.

Yang, C. (2000). A variable rate applicator for controlling rates of two liquid fertilizers. Appl Eng Agric, 17(3), 409-417.

Yang, C., Everitt, J. H., \& Bradford, J. M. (2000). Comparison of uniform and variable rate nitrogen and phosphorus fertilizer applications for grain sorghum. Trans ASABE, 44(2), 201-209.

\section{Copyrights}

Copyright for this article is retained by the author(s), with first publication rights granted to the journal.

This is an open-access article distributed under the terms and conditions of the Creative Commons Attribution license (http://creativecommons.org/licenses/by/4.0/). 